\title{
Inter-agency Cooperation and New Approaches to Employability
}

\section{Colin Lindsay, Ronald W. McQuaid and Matthew Dutton}

\begin{abstract}
This article examines the role of inter-agency cooperation, which is one form of 'partnership', in new approaches to employability in the UK. The article articulates a 'model for effective partnership working' on employability. This model is applied first in a general review of employability policy and then to discuss case study research on the recent 'Pathways to Work' and 'Working Neighbourhoods' pilots. It is argued that successful partnerships need a clear strategic focus based on a necessity for inter-agency cooperation and institutional arrangements that allow for shared ownership, trust and mutualism, and flexibility in resource-sharing. While some of these factors are apparent in UK employability services, an over-reliance on contractualism and centralized organizational structures may undermine partnership-based approaches. Many of the success factors associated with effective partnership working appeared to be in place, even though the role of the Public Employment Service was fundamentally different in each case (as a key actor in implementing the first pilot, but largely withdrawing from the implementation role in the second). The article concludes by outlining the relevance of this model and the case study findings to discussions of the future development of employability policies and related partnership working.
\end{abstract}

\section{Keywords}

Unemployment; Employability; Partnership; Activation; Pathways to Work

\section{Introduction}

Inter-agency cooperation is one form of 'partnership', involving government departments, public bodies, private companies and the third sector that has emerged as a core element of policies to promote employability. New approaches to employability policy being tested by the UK government and devolved administrations continue to emphasize the need for multi-agency strategies for tackling the multidimensional barriers to work faced by

Address for correspondence: Colin Lindsay, Employment Research Institute, Napier University Business School, Craiglockhart Campus, Edinburgh,EHI4 IDf. Email: c.lindsay@napier.ac.uk 
disadvantaged job-seekers (Scottish Executive 2006; HM Treasury 2007). Furthermore, at the supranational level, the European Employment Strategy has increasingly incorporated a partnership dimension, particularly through calls for the involvement of local stakeholders in, and 'progressive de-monopolization' of, employment services (European Commission 2005).

This article discusses the role of partnership in UK employability policy (with particular reference to two recent innovative pilot programmes) and identifies issues and problems around the establishment of effective partnership working. Following this introduction the article is structured as follows. The section below discusses conceptual issues around partnership and inter-agency cooperation, and reviews the benefits sought by policy-makers who promote partnership working in employability and other areas of public policy. Then the literature on 'conceptualising successful partnerships' (Dowling et al. 2004) and 'critical success factors in partnerships' (McQuaid et al. 2005) is drawn on to present a model for effective partnership working. After a discussion of the context of current UK employability policy, the next two sections describe the findings of case study research focusing on 'Pathways to Work' and 'Working Neighbourhoods' pilot programmes. We conclude by outlining the relevance of our model for effective partnership working to these findings and discuss implications for policy.

\section{The Concept of Partnership and Inter-agency Cooperation}

\section{Defining partnership}

As inter-agency cooperation has emerged as a sine qua non of social policy, concerns have been raised that 'partnership' itself has become a 'woolly concept' (Lyons and Hamlin I99I: 55; Hudson and Hardy 2002) that is little more than a policy buzzword (Ranade and Hudson 2003) - an idea so ubiquitous in major policy initiatives that it defies definition and risks losing analytical value (Diamond 2006). Given the numerous contexts within which partnership has been deployed, there have been a number of attempts to provide a framework for understanding the concept - see McQuaid (I994, 2000), Hutchinson and Campbell (I998) and Dowling et al. (2004). For the purposes of this discussion we adopt Stoker's (1998) broad-based understanding of the concept of partnership as including three forms:

- principal-agent relations (including purchaser-provider relationships favoured under the contracting-out of public services);

- inter-organizational negotiation (the coordination of resources and capabilities, for example through multi-agency delivery partnerships);

- systemic coordination (embedded multi-agency governance based on a shared vision and institutionalized joint working to the extent that selfgoverning networks emerge).

There is value in adopting such a broad-based definition. It is inclusive enough to embrace many of the main forms of planning and delivery arrangements in public policy. It allows for comparison within and between 
these different models of cooperation, and enables us to track changes in policy and governance (covering, for example, the inter-relationships between formal strategic partnerships, service level agreements and contracting-out). However, Stoker's inclusion of principal-agent contracting as a form of partnership raises a number of issues. The differential power relations associated with principal-agent contracting clearly contrast with more traditional definitions of 'partnering'. For Powell and Exworthy (2002) trust is a key feature of the kind of 'networked governance' that defines genuine partnership - contractual relations which enforce obligations based on unequal power represent a different form of relationship. Nevertheless, as Rummery (2002: 236) notes:

A degree of caution is required before it can be asserted that contractual relationships are not built on trust and therefore partnerships and contracts are mutually exclusive. Even if it is accepted that trust is a defining characteristic of partnership, it does not necessarily follow that contracts play no role in facilitating successful partnerships.

Furthermore, in the UK, while the current Labour government has retained purchaser-provider splits, it has also mandated agencies to collaborate in order to overcome problems of fragmentation that had resulted from rapid marketization during the Conservative era (Miller and Ahmad 2000). To some extent there has been a greater emphasis on engagement with the voluntary sector and a focus on engendering cooperation by 'less formal and more egalitarian means' (Ranade and Hudson 2003: 36). Stoker's broad-based conceptualization of partnership therefore reflects the more sophisticated rationale for the inter-agency approaches that is sometimes not acknowledged by critics of 'new public management'. Rather than simply seeking to impose private sector inputs, policy-makers have clearly also been drawn towards contracting-out and other inter-agency approaches by an acknowledgement of the multiple forms of disadvantage faced by some people, which require multidimensional approaches.

\section{Benefits of partnership}

Much of the literature on inter-agency cooperation (whether referring to principal-agent contractual relations, inter-organizational negotiation or systemic coordination) tends to set out a familiar range of potential 'partnership benefits'.

- Flexible and responsive policy solutions - Perhaps one of the most regularly deployed arguments in favour of partnership-based approaches is that problems of social and labour market exclusion are multi-dimensional, requiring a range of inputs from a variety of specialist stakeholders (e.g. Rhodes et al. 2003). Within employability interventions, partnerships can facilitate the tailoring of programme delivery to the problems of specific client groups and opportunities of local labour markets (McQuaid and Lindsay 2005; Sunley et al. 2006). The availability of different stakeholders 
to participate in delivery also allows for 'considerable fluidity ... because they allow issues to be taken up or shelved, or passed between groups' (Hardiman 2006: 344).

- Facilitating innovation - Partnerships can have greater scope to test innovative approaches. The fact that stakeholders come together from a range of different policy perspectives can, in itself, produce greater dynamism through the sharing of ideas, expertise and practice. Effective partnership working challenges existing approaches by bringing to bear experience from other sectors, and developing new ways of working (Nelson and Zadek 2000).

- Sharing knoweledge and expertise - A defining feature of partnership working is the manner in which skills, knowledge and expertise are shared to try to maximize the quality and efficiency of services. By engaging with other public, private and third sector agencies with expertise in specific areas of provision, or with experience in working with particularly disadvantaged areas or groups or with employers, providers can improve the reach, diversity and quality of their services. Evidence from local employability initiatives suggests that the development of improved data-sharing systems across such partners can also lead to more consistent and effective services (Shaw 2007).

- Pooling of resources and 'bending the spend' - At the most basic level, partnershipbased approaches can increase the total level of resources brought to bear on problems, by increasing the number of budget-holding organizations and the scale and types of resources involved in solutions (Rhodes et al. 2003). However, it is in targeting mainstream expenditure on specific shared goals ('bending the spend'), and so maximizing the impact of resources, that partnerships are seen as having greatest impact, especially in the long term. For example, 'mainstreaming employability' as a supplementary goal for healthcare or childcare services has emerged as a key priority for policy-makers (Scottish Executive 2006; HM Treasury 2007). Beyond the pooling of financial resources, 'partnership synergy' can emerge from the alignment of policies to achieve complementary goals (for example, across health, regeneration and employability agendas) (Hemphill et al. 2006).

- Building capacity in organizations and communities - Examples of best practice in regeneration projects in England have demonstrated that local partnerships can build community capacity by providing additional resources and sharing policy responsibility (Rhodes et al. 2003). For the voluntary sector, cooperation with government also offers new opportunities to have a practical impact on the policy agenda, but there remain concerns that the independence of such community-based organizations can be undermined by the unequal power (especially over resources) that characterize many 'partnerships' (Somers and Bradford 2007). At a more basic level, the limited capacity and resources within the voluntary and community sectors continue to limit their ability to fully engage in the employability and other policy agendas (Taylor 2006).

- Tapping local knowledge, legitimizing policy and mobilizing support - The tapping of 'local knowledge' through the involvement of community-level stakeholders 
can contribute to the development of approaches that are better able to address localized problems. Engaging a range of stakeholders can also result in the legitimization of, and mobilization of support for, new strategies (Carley 2006). For example, a local authority-led project may gain greater legitimacy among potential participants or clients in a neighbourhood project by involving suitable local community bodies. It is therefore important that local partners are able to legitimately represent, and carry the support of, communities (Mason 2007).

\section{Towards a Model for Effective Partnership Working}

A number of studies have sought to identify lessons from successful partnership initiatives. The discussion below draws on previous research and recent studies on 'conceptualising successful partnerships' (Dowling et al. 2004) and 'critical success factors in partnerships' (McQuaid et al. 2005). Reviewing this and more recent literature, a number of recurring features can be identified as appearing to be important to the success of partnerships.

\section{Strategic focus}

Successful models of inter-agency cooperation tend to be governed by a detailed, clearly defined strategy and remit, a commitment to shared objectives and clear targets informed by an overarching strategic vision. Within the employability policy context, McQuaid et al. (2005) emphasize the need for transparency in operations (in terms of decision-making and resource allocation) and a non-instrumental approach by partners, so that strategic interests are given priority over local or sectional interests. Where commitment to shared values and a common focus - what Carley (2006) calls an integrated policy culture - becomes fragmented, a 'drift away from ideals of participation' (Geoghegan and Powell 2006: 859) and the disintegration of partnership working can quickly follow.

\section{Commitment of necessary stakeholders}

Effective partnerships need the right mix of skills and expertise, and a recognized and legitimate role for all partners able to make a contribution to shared policy goals (Hudson and Hardy 2002; Rhodes et al. 2003). However, it is important for partnerships to be clearly focused - Blaxter et al. (2003) and McQuaid et al. (2005) reflect on successful local employability projects, noting that only appropriate stakeholders with the power, skills or resources (including, for instance, symbolic resources which may increase the legitimization of the project among target groups or potential funders) to add value to the partnership were included.

\section{Organizational complementarity and coterminosity}

The engagement of organizations that 'match' and complement each other's resources and areas of expertise appears to be important to maximizing the 
benefits of partnerships. The presence of common or complementary goals is important, as is the degree of 'symbiotic inter-dependency' - the extent to which benefits for one partner agency produce mutually beneficial outcomes for other partners (Fenger and Kok 200I). At a basic, practical level partnership working may be easier where participants operate within coterminous, or at least similar, organizational/geographical boundaries, by easing communication and reducing the inefficient duplication of activities (Diamond 2006).

\section{Capacity for cooperation and mutualism}

It is important that those involved in partnerships have both the authority and institutional flexibility to engage in mutual decision-making and resource-sharing. At the organizational level, successful partnerships tend to be integrated within local governance structures, allowing decisions to be actioned through existing bodies (Carley 2006). Geddes et al. (2007) note that the willingness of government to share leadership with others can result in a virtuous circle of increasing commitment and participation from non-funding stakeholders. However, it is worth noting that partnerships may have considerable costs, requiring the commitment of time, administrative and other resources - some partners may be unable to provide these, or costs may outweigh the benefits of partnership in some cases (McQuaid 2000).

\section{Trust and reciprocity}

Trust can be seen as forming the basis for the commitment required for successful partnerships, and as a prerequisite for 'sufficiently high levels of communication to facilitate the sharing of knowledge' (Casey 2007: 5). Where status is not equal, the distribution of power and influence should be demonstrably appropriate (Powell and Dowling 2006). As noted above, the dominance of contracting-out in many areas of public policy has resulted in concerns being raised regarding the extent to which such arrangements are conducive to relationships of trust. Apart from the fundamentally different nature of contractual relations, it has been suggested that the expansion of private sector-oriented processes can create tensions - non-profit sector bodies have displayed a reluctance to replicate commercial forms of behaviour (Taylor 2006).

\section{Outcome-oriented focus}

Finally, Dowling et al. (2004) highlight the need to move beyond discussions of the process of partnership working to talk about outcomes. While the success factors discussed above can be seen as contributing to effectiveness in the process of partnership, 'outcome success' is crucial, as reflected in evidence of improved accessibility, efficiency, effectiveness and quality in services and (crucially) improvements in the outcomes experienced by end users. Measurable goals that can be clearly defined and evaluated, and an emphasis on the quality and distribution as well as the quantity of outcomes, are important. Without clearly defined goals and outcomes, there is a danger 
that partnerships can be drawn into the minutiae of the process, rather than focusing on implementing change (Ball and Maginn 2005).

\section{Partnership and Employability Policy in the UK}

The Labour government elected in I997 has consistently deployed the language of partnership in relation to its attempts to reform the governance and delivery of employability policy in the UK. The New Deal - the UK's main group of compulsory active labour market programmes established since I997 - was initially designed and implemented at the local level through I44 'New Deal Partnerships', led by the Public Employment Service (PES), but including a range of other public, private and third sector actors (Sunley et al. 2006). During the early stages of the programme's development, the government also encouraged experimentation in local partnership models. However, local experimentation quickly gave way to a 'safety first' approach, with the PES assuming the sole lead role in many areas in order to avoid the need for more complex organizational arrangements (Lindsay 2007).

The concept of partnership has remained central to UK employability strategies. Employment Zones, which have operated in areas of particularly high unemployment since I998, contract out key PES employability services to single or multiple private sector 'Lead Partners', which then often subcontract aspects of delivery to a range of other agencies (Bruttel 2005). Recent proposals for the establishment of 'City Consortia' in disadvantaged urban areas seek to more effectively link employability, health and social services 'to pool resources and expertise in order to tackle unemployment' (HM Treasury 2006: 46), while 'Local Employment Partnerships' are being formed to strengthen relationships between the PES and major employers through demand-led services (HM Treasury 2007).

There is evidence that some of the benefits discussed above have been achieved by policy-makers' continuing attempts to promote inter-agency working on employability. It has been suggested that the 'opening up' of the delivery of employability services to include the private and third sectors (produced by the first wave of New Deal reforms) has had some positive impacts on the diversity of provision available to job-seekers, while helping to build capacity among voluntary organizations (Finn 2003). Nevertheless, the continued domination of the PES as funder and manager has been the focus of a consistent criticism of the New Deal, Employment Zones and other contract-based programmes (Bruttel 2005). The UK system's 'centralized localism' (Lødemel 200I) means that the PES still largely controls the design and content of programmes, with local 'partners' tendering to provide agreed services within a set contracting structure. Multi-agency 'New Deal Partnerships' have given way to a simple contracting regime with private and third sector providers competing for PES resources - 'the "top-down" system of delivery and control ... has not been substantially challenged' (Trickey and Walker 200I: 203).

Despite these problems, the New Deal and linked policies have been hailed as a success by government and, with general unemployment having declined, recent pilot programmes have increasingly sought to expand the 
reach of employability strategies to target hard-to-reach areas and groups (DWP 2006). Introduced from 2003, 'Pathways to Work' (PtW) pilots provided new health and employability services for clients claiming incapacity benefits. 'Working Neighbourhoods' (WN) pilots, which ran from 2004 to 2006 and have since influenced the government's current City Consortia policy, targeted additional resources on active labour market initiatives in communities characterized by particularly high levels of economic inactivity. These two pilots formed the focus for our case study research. In both cases, there was an attempt to encourage new forms of partnership working, but they also present contrasts: in the PtW case the PES retained a key implementation role while expanding services to clients through partnership with the National Health Service (and other specialist agencies), while in the WN pilot the PES had little role in implementation, with a private contractor instead delivering services and coordinating multi-agency approaches.

\section{Case Study I: Pathways to Work}

\section{Background and methodology}

Since 2003, PtW has established partnerships between the PES (Jobcentre Plus), specialist providers and the NHS to support people claiming incapacity benefits to make progress towards work. This is partly in response to the high levels of incapacity benefit (the level of which is much greater than that of unemployment), the extremely low numbers of people that have historically moved from incapacity benefits back into work, and demographic changes leading to the desire to keep more workers with minor health problems in the labour market. The programme was initially piloted in seven delivery areas, then extended to a further $\mathrm{I} 5$ areas in $2005^{-6}$, and is being rolled out to cover all of the UK by the end of 2008.

The government has described PtW as offering 'a new intervention regime to activate people's aspirations to return to work' (DWP 2004: I6) - the first step in a process of activating the incapacity benefits regime in order to 'focus on what people are capable of doing'. All new benefits claimants (and in some areas those who started claiming during the two years preceding the introduction of the programme) are eligible. PtW content includes:

- a compulsory assessment interview, followed by five compulsory workfocused interviews with PES Personal Advisers (PAs);

- voluntary access to short 'Choices' training options (e.g. 'work preparation programmes' that provide basic employability skills delivered by training providers and employers);

- a one-year 'Return to Work Credit' paid at £40 per week tax-free for full-time work;

- a Condition Management Programme (CMP) - a 6-I3-week voluntary intervention designed to enable clients to cope with 'moderate medical conditions' (mainly mental health, cardio-respiratory, and musculo-skeletal conditions). In the case study area, CMP services were entirely delivered by NHS clinical professionals. 
The case study research focused on the piloting of the programme in a mainly peri-urban/urban PES district in central Scotland. The research was conducted in February-March 2006 and involved a review of policy and evaluation documents and in-depth interviews with senior 'innovations unit' and operational managers (at regional level) within the PES; and delivery staff and managers and senior project directors within the NHS (six interviews conducted during two case study visits).

\section{Approaches to partnership}

In the case study area, the PES led and funded the delivery of PtW. PES officers based at Jobcentre Plus offices also provided Personal Adviser (PA) services in some areas, dealing with initial assessment and referring clients to various service options, contracted out to a range of private and third sector employability providers. Crucially, however, the CMP, arguably the most innovative feature of $\mathrm{PtW}$, was delivered through the NHS in the case study areas (where the relevant regional NHS Board acted as the budget holder and commissioning body for the CMP, while delivery was the responsibility of the local Primary (Health) Care Trust, which employed the healthcare professionals who worked with PtW clients). The CMP took some of the key principles of cognitive behaviour therapy (CBT) as its starting point. ${ }^{1}$ These therapeutic principles were supplemented within a highly flexible programme that also included other elements of behavioural therapy and advice on exercise, diet and pain management.

Two important themes to emerge from our interviews with key stakeholders were: first, that the capacity and expertise arising from the inclusion of the NHS as a strategic and delivery partner delivered clear benefits; and second, that those benefits were maximized as a result of the flexible partnership model developed under PtW. The inclusion of highly skilled NHS professionals brought considerable knowledge and expertise to the CMP process, a benefit acknowledged by PES managers. CMP practitioners were also able to refer to, and utilize, the wealth of expertise located elsewhere within the NHS (see also Lindsay et al. 2007).

'We have great strength in depth. On our team we have people who specialize in: drug and alcohol addiction; acute mental healthcare; mental health rehab; community physical healthcare; physiotherapists; occupational therapists; learning disability specialists. We've got a great pool of knowledge [and] we can also refer into other statutory health services if we need to.' (NHS interviewee)

It was also suggested that the involvement of NHS professionals reassured clients that the CMP was a credible service with the capacity (and aim) to positively impact upon their health. Previous attempts to 'activate' claimants of incapacity benefits have generated hostility among many, who have seen compulsory activities as an attempt to force them into work. Both PES and health professionals involved in PtW suggested that the participation of NHS staff in the CMP helped to legitimize this element of the pilot.

As noted above, the partnership model developed under the PtW pilot in the case study area was also more flexible (and more oriented towards 
cooperation) than under many of Jobcentre Plus's contracted-out services. At the outset of the pilot, activities focused on joint working and shared learning - for example, prior to the development of the CMP, NHS and PES staff jointly carried out in-depth interviews with more than Ioo prospective clients, providing an insight into the range of issues faced by individuals but also allowing for health and employment professionals to understand each other's roles and capacities. This emphasis on shared learning was continued into the operational phase of the pilot. In some cases NHS professionals worked alongside Jobcentre Plus PAs during initial assessment interviews with clients, allowing these PAs to learn more about the content of the CMP and improving their assessment of the potential benefits for individuals.

The funding and management model established by Jobcentre Plus for this pilot appears to have been crucial to facilitating cooperation between the agencies. At the outset of the pilot, PES managers agreed to replace standard contractual models with more flexible financial structures, allowing NHS managers considerable freedom in the recruitment of staff and resourcing of programme development. Comprehensive memoranda of understanding detailed the roles and responsibilities of each partner, but mutually agreed targets focused on engaging and progressing clients, rather than merely registering short-term job outcomes.

Both NHS and PES interviewees pointed to the innovative funding structures piloted under PtW as contributing to the flexibility of the pilot. For NHS stakeholders, the autonomy given to CMP managers to manage their own budgets enabled staff to move between roles in order to address service gaps without delay, and allowed for the modification of programme content to meet clients' needs. For PES managers, there was value in experimenting with more flexible partnership models that reduced the need for contract management and bureaucratic 'hand-offs' (formal procedures transferring responsibility for clients between agencies).

'We realized the need for a different kind of approach. We developed a model that was more informal and client-centred; we tried to cut out "hand-offs" and referrals so that the client received a seamless service. We have tried to develop a more informal process . . . rather than depending on lots of paperwork.' (PES interviewee)

There were some problems associated with ensuring that all PES systems were supportive of the PtW process. A 'Personal Capability Assessment' medical examination commissioned by Jobcentre Plus separately from PtW activities sometimes saw Incapacity Benefit claimants who had begun to make progress through CMP participation 'passed as fit', so that their welfare benefit claims were terminated. Although CMP therapists described an increasingly coherent relationship with medical professionals carrying out Personal Capability Assessments for Jobcentre Plus, there is evidence that clients who have had their claim terminated in this way are reluctant to re-engage with PtW (Barnes and Hudson 2006).

Despite these problems, the innovative partnership described above allowed for an effective combination of PA services delivered by experienced PES staff, and CMP therapies delivered by health professionals, representing 
a step forward in joint working and the sharing of practice. The results from this and other PtW pilots were broadly encouraging. PtW pilots generally delivered significant employment impacts (Blyth 2006), and research with CMP participants has suggested that there have been benefits in assisting people to cope with work (Corden and Nice 2006) and 'softer' outcomes such as improvements in self-esteem, increased functioning, and decreased reliance on medication (Barnes and Hudson 2006).

Where positive outcomes have been achieved by $\mathrm{PtW}$, it is unclear to what extent the partnership models developed in different areas have impacted on success rates. What is clear from our research is that many of the innovative features of the pilot (such as flexible approaches to the recruitment, remuneration and deployment of expert NHS staff) would not have been achievable under more rigid contractual models, and that the level of expertise and credibility brought to the CMP by health professionals would not have been available without the active participation of the NHS. It is therefore a matter of concern that the government has suggested that 'future PtW provision will be delivered primarily by the private and voluntary sectors, with payment by results' (HM Treasury 2006: 43).

\section{Case Study 2: Working Neighbourhoods}

\section{Background and methodology}

Working Neighbourhoods (WN) - a pilot programme directly funded by HM Treasury - ran from 2004 to 2006. The pilot sought to target additional resources, encourage innovation, and respond to the needs of communities characterized by high levels of economic inactivity (where 'standard' labour market policies were perceived to have had limited impact). Twelve localities were targeted, with each WN area able to access the resources and services available through mainstream programmes such as New Deal, but also allocated an annual Flexible Discretionary Fund of approximately fI million. In pilot areas, the PES was restricted to administering benefits, while (often private sector) main contractors or 'Lead Partners' were charged with delivering or contracting out PA assistance and a range of other holistic services. The WN approach therefore sought to integrate a range of interdisciplinary services under a single partnership agreement, with a Lead Partner contractor coordinating, subcontracting and in some cases delivering services. Implementation was largely devolved from the PES to the Lead Partner (unlike our PtW case study area, where the PES maintained a key implementation role and expanded services to clients through partnership with specialist agencies).

The case study research focused on the piloting of the programme in one area of a major English city, where delivery was led by a subsidiary of a private sector employment and training agency. A review of policy and evaluation documents was supplemented by two case study visits and four in-depth interviews with: the $\mathrm{CEO}$ and a senior company manager within the WN Lead Partner; the Lead Partner's national director of employability services (who was previously closely involved in the development of services 
in the case study area); and the local project manager leading the delivery of the WN pilot.

\section{Approaches to partnership}

At a strategic level, the WN pilot was overseen by a partnership between the private sector lead delivery partner, the PES, the Local Strategic Partnership, the local authority and other key stakeholders. The WN model in the pilot area centred around what one evaluation has called a 'hub and spoke' approach, where a multi-use service centre was established as a community hub, allowing for the co-location of services for both WN clients and other local residents - 'A key advantage of this model was that advisers could not only refer customers to appropriate provision, but in most cases accompany them to another part of the office and introduce them to staff working for the partner agency' (Dewson et al. 2007: 4I). As well as providing the base for the Lead Partner and other providers to deliver employability services, the WN hub was designed to offer a focal point for the community, providing free IT, sports, meeting and childcare facilities.

Lead Partner interviewees consistently pointed to the importance of the hub approach as a means of raising awareness and establishing credibility within the local community. By providing space and support for the activities of community groups, the WN Lead Partner was able to identify new 'referral routes' and so engage with a broader population of clients; and establish trust within the local community (as well as contributing to capacity-building among local organizations, which were able to extend and diversify their own activities).

'We view our involvement in the community to be of paramount importance to the success of the project. This approach [supporting sport and social groups] has encouraged positive activities for local children, while providing an invaluable link with parents in order to raise awareness of the WN pilot.' (WN Lead Partner interviewee)

There is an extent to which such comments reflect the rhetoric of partnership that has become established in discussions of public policy, but it is important to note that the Lead Partner delivered substantial practical support for community organizations by providing resources and accommodation for their activities.

Employability provision focused on: the delivery of PA services (by 'employment coaches' employed by the Lead Partner); additional assistance from dedicated job matching and benefits advice staff; and a structured pre-vocational employability programme delivered by the Lead Partner. This provision was supplemented by services based within the WN hub focusing on: skills assessment and development advice delivered by the government's LearnDirect agency; specialist learning services; debt advice provided by local voluntary organizations; and financial support from a newly formed credit union.

Together, the range of services offered through WN constituted a recognition that the problems faced by job-seekers are multidimensional, requiring 
multi-agency responses. The WN Lead Partner was clear that even large national providers 'can't do it all alone'. Partnerships were built with specialist providers and community organizations identified as being able to add value to existing provision. As in our previous case study, the flexible funding model allowed under the pilot appeared to promote a more partnershiporiented approach. It should, of course, be acknowledged that the Lead Partner (and its government funder) set the broad parameters for others' activities, but the absence of rigid contractual obligations and targets may have opened the way to a more inclusive delivery model. Indeed, the WN Lead Partner acknowledged that while its own contract was awarded on the basis of a commitment to achieving 'job entry' and 'sustained employment' targets, flexible internal funding and administrative processes within WN meant that partner organizations were not put off by the threat of centrally imposed, rigid performance indicators.

'Our work with local delivery organizations was based on a series of discussions where we established a shared understanding. We didn't seek to impose rigorous targets. We were more concerned that organizations acted in line with our shared beliefs and values, rather than undertake activity for activity's sake.' (WN Lead Partner interviewee)

The job entry and sustained employment outcomes reported by $\mathrm{WN}$ in the case study area exceeded targets. The national performance of the pilot programme in terms of partnership formation and employment outcomes was variable but generally encouraging. Evaluations pointed to problems with engaging the most vulnerable, a symptom of the limited and short-term funding for WN pilots, together with an overall emphasis on promoting immediate job entry for clients where possible (Dewson 2005; Lindsay et al. 2007). It was notable that in our WN pilot area relatively limited progress had been made in addressing the needs of those claiming incapacity benefits and other 'economically inactive' people (many of whom want to work but face substantial barriers to participation) - it was explained that these people were 'not the target group'. There was also some evidence of a reluctance to acknowledge some of the more complex barriers (such as literacy issues) faced by some hard-to-reach job-seekers, which might take longer and be more expensive to ameliorate. Nevertheless, WN pilots generally saw more people assisted to progress into more sustained employment than in comparable areas where pilots were not in operation.

As in our first case study, it is difficult to establish a causal link between job outcomes and partnership-based service delivery. However, evaluations of the WN programme have suggested that the combination of PA support and a wide range of other community-based services were valued by participants (Dewson 2005). The 'holistic approach' developed by WN partnerships appears to have delivered benefits not just in addressing individuals' barriers to work but in 'general aspects of their lives such as health, finance, family and housing, which are not always directly related to labour market participation' (Dewson et al. 2007: 43). It may be suggested that such holistic approaches (and benefits) are more likely to emerge from partnerships that are sufficiently 
flexible to allow for the inclusion of partners with a range of expertise in employability. Even if the impact of effective partnership working on job outcomes is difficult to quantify, it is clear that the flexible and inclusive management and funding model developed under the WN pilot (in contrast to more rigid forms of contracting that characterize many mainstream Jobcentre Plus programmes) allowed for the inclusion of a wider range of stakeholders and the emergence of more holistic services for job-seekers.

\section{Discussion and Conclusions}

The pilots discussed above reported important successes, both in building effective systems of inter-agency cooperation and in achieving the outcomes sought for clients. Many of the success factors associated with our model for effective partnership working appeared to be in place, even though the role of the PES was fundamentally different in each case (with it being a main actor in implementing the PtW pilot, but largely giving up the implementation role to a Lead Partner contractor under WN). In both cases, pilots had a clear strategic focus and rationale for joint action (for PtW, the need to address the complex problems faced by people claiming incapacity benefits; for WN, an acknowledgement of the need for multi-agency approaches to tackling multiple disadvantage in inner-city areas). It is notable that different agencies were able to articulate this shared strategic focus through a range of partnership agreements (including memoranda of understanding) without always resorting to contracts comprehensively detailing required actions and outcomes. It seems clear that the pilots' relatively flexible funding and governance arrangements contributed to the commitment of necessary stakeholders - another of our critical success factors. For example, in the case of PtW the unique capacity, credibility and expertise brought to the pilot by NHS involvement was a key success factor. In both cases, there is evidence that simple contractingout mechanisms would not have been able to so effectively assemble the same array of expertise gathered to deliver pilot activities (and which contributed to multidimensional services responding to job-seekers' complex needs).

Under both pilots, there was also clear complementarity between PES/Lead Partners' core employability provision and the holistic range of services (ranging from debt counselling to cognitive behavioural therapy to childcare assistance) delivered by other organizations and which the PES acknowledged that it did not have the capacity or expertise to provide. In practical terms, coterminosity and co-location appear to have facilitated effective communication between agencies and seamless services for job seekers - PtW saw health professionals share practice with PES officers in Jobcentres, while the WN hub model co-located employability, learning and financial services in one centre.

However, most important was the capacity for cooperation and mutualism demonstrated by the PES and its partners in both cases. Each pilot replaced the rigid, centralized contractual model associated with standardized PES services with more flexible funding and governance structures. Detailed memoranda of understanding and partnership agreements made clear what was expected of each participating organization, but also allowed for flexibility in the selection and resourcing of services, enabled changes to service content 
to be made as required, and minimized transaction costs and client transfer (or 'hand-off') bureaucracy. Strong lines of trust and reciprocity, rather than the demands of contract agreements, characterized relationships between lead partners and other participating organizations. By sharing ownership of (rather than dictating) programme development and delivery, Lead Partners were able to draw on the capacity of expert partners and ensure that these organizations had a stake in, and sense of responsibility for, seeing that interventions worked.

Finally, both pilots can be seen as demonstrating an outcome-oriented focus, but also a degree of sophistication in seeking to move beyond simplistic job entry statistics. In the case of the PtW pilot, while a strong focus on outcomes was retained, NHS professionals were charged primarily with engaging and progressing clients, rather than pursuing quick job entries - a softening of Jobcentre Plus's so-called 'work first' ethos (Lindsay et al. 2007). While the WN Lead Partners were set challenging job entry targets by government, they were also granted considerable autonomy to run their internal funding and administrative processes (so that performance and outcome targets were not imposed on WN partners if inappropriate).

As we have noted above, establishing a causal link between the outcomes achieved by employability interventions and models of governance and delivery is fraught with difficulty. Questions of attribution and problems in identifying precise parameters for measuring success or failure also present challenges for those interested in studying the impact of effective partnership working (Mason 2007). However, it is clear that the programmes described above reported some notable successes in achieving their target outcomes; that our research and qualitative evaluation evidence from elsewhere highlight the importance of holistic, multidimensional services in delivering positive outcomes; and that the development of such services was substantially assisted by flexible, partnership-based governance, management and delivery.

For the UK government to effectively mainstream the benefits of these pilots (through the extension of PtW or the development of WN-type interventions under new City Consortia) there needs to be a commitment to moving beyond the 'centralized localism' that seeks to access the benefits of engaging expert organizations in the delivery of local services, but imposes a centrally managed, rigid contractual regime that constrains the ability of both the PES and partner organizations to respond to the needs of clients and communities. Yet the national roll-out of PtW may see a return to rigid contracting mechanisms and a greater emphasis on immediate job entry as the dominant outcome target for (mostly private sector) service providers. City Consortia and other local partnerships are still in development at the time of writing, but previous attempts to roll out innovative targeted initiatives such as Employment Zones have suffered from a retreat from flexible partnership models tested under pilots (Bruttel 2005). This raises questions around policy learning, if major components of pilot projects (including forms of partnership working) are then fundamentally altered in the mainstreaming of policies without adequate testing.

As Diamond (2006: 28I) notes, the rhetoric of partnership has been overused in the UK, while there has been limited progress in embedding change 
through the fundamental reform of organizational practice and culture. The 'rush to partnership' has placed 'multiple and contradictory demands' on government (at all levels) and other stakeholders, running the risk of 'partnership fatigue'. Meanwhile, government's reliance on dirigiste, topdown management and centralized contracting means that there has been only a 'rhetorical shift away from a centralized monolithic policy model towards a greater element of local flexibility' (Sunley et al. 2006: 156).

Our findings concur with the idea that there is a need to grasp the significance of local and regional networks and to consider the potential role of different forms of relationship in the governance and delivery of employability and other area-based policies (Diamond 2006). This may require a combination of models of contracting-out that allow 'freedom between the provider and the individual to do what works best for them' (Freud 2007: 6), working alongside new forms of partnership defined by flexible funding, governance and management (and shared ownership of the development and delivery of interventions). It is important that policy-makers' acknowledgement of the multidimensional barriers faced by disadvantaged job-seekers is matched by a renewed commitment to flexible, innovative approaches to promoting employability. The experience of pilot initiatives is that such flexibility and innovation flows from relationships based on cooperation and mutualism, rather than the micro-managed contractualism that has often characterized the governance of employability policies in the UK.

\section{Acknowledgement}

The research reported in this article was supported by the Department for Employment and Learning, Northern Ireland. All views are those of the authors. We are grateful for the helpful comments of two anonymous referees.

\section{Note}

I. CBT is based around 'bio-psycho-social' approaches to behaviour modification. It uses a combination of cognitive and behavioural techniques to challenge harmful attitudes and behaviours, empowering the individual to overcome negative selfimage and dysfunctional behaviour.

\section{References}

Ball, M. and Maginn, P. J. (2005), Urban change and conflict: evaluating the role of partnerships in urban regeneration in the UK, Housing Studies, 2, I: 9-28.

Barnes, H. and Hudson, M. (2006), Pathways to Work: Qualitative Research on the Condition Management Programme, Department for Work and Pensions (DWP) Research Report 346, London: DWP.

Blaxter, L., Farnell, R. and Watts, J. (2003), Difference, ambiguity and the potential for learning: local communities working in partnership with local government, Community Development Fournal, 38, 2: 130-9.

Blyth, B. (2006), Incapacity Benefit Reforms: Pathways to Work Pilots, Department for Work and Pensions (DWP) Research Report 26, London: DWP.

Bruttel, O. (2005), Are Employment Zones successful? Evidence from the first four years, Local Economy, 20, 4: 389-403. 
Carley, M. (2006), Partnership and statutory local governance in a devolved Scotland, International fournal of Public Sector Management, I9, 3: 250-6o.

Casey, M. (2007), Partnership: success factors of inter-organizational relationships, Fournal of Nursing Management, i6, г: 72-83.

Corden, A. and Nice, K. (2006), Pathways to Work: Findings from the Final Cohort in a Qualitative Longitudinal Panel of Incapacity Benefit Recipients, Department for Work and Pensions (DWP) Research Report 398, London: DWP.

Dewson, S. (2005), Evaluation of the Working Neighbourhoods Pilot: Year One, DWP Research Report 297, London: DWP.

Dewson, S., Casebourne, J., Darlow, A., Bickerstaffe, T., Fletcher, D., Gore, T. and Krishnan, S. (2007), Evaluation of the Working Neighbourhoods Pilot: Final Report, DWP Research Report 4II, London: DWP.

Diamond, J. (2006), Au revoir to partnerships: what's next? International Fournal of Public Sector Management, I9, 3: 278-86.

Dowling, B., Powell, M. and Glendinning, C. (2004), Conceptualising successful partnerships, Health and Social Care in the Community, I2, 4: 309-17.

DWP (Department for Work and Pensions) (2004), Building on New Deal, Sheffield: DWP.

DWP (Department for Work and Pensions) (2006), A New Deal for Welfare: Empowering People to Work, London: DWP.

European Commission (2005), Guidelines for the Employment Policies of Member States, Brussels: European Commission.

Fenger, M. and Kok, P. J. (200I), Interdependency, beliefs and coalition behavior: a contribution to the advocacy coalition framework, Policy Sciences, 34, 2: 157-70.

Finn, D. (2003), The 'employment-first' welfare state: lessons from the New Deal for Young People, Social Policy \& Administration, 37, 7: 709-24.

Freud, D. (2007), Reducing Dependency, Increasing Opportunity: Options for the Future of Welfare to Work, London: DWP.

Geddes, M., Davies, J. and Fuller, C. (2007), Evaluating local strategic partnerships: theory and practice of change, Local Government Studies, 33, I: 97-1 I6.

Geoghegan, M. and Powell, F. (2006), Community development, partnership governance and dilemmas of professionalization: profiling and assessing the case of Ireland, British Fournal of Social Work, 36, 5: 845-6I.

Hardiman, N. (2006), Politics and social partnership: flexible network governance, Economic and Social Review, 37, 3: 343-74.

Hemphill, L., McGreal, S., Berry, J. and Watson, S. (2006), Leadership, power and multi-sector urban regeneration partnerships, Urban Studies, 43, I: 59-80.

HM Treasury (2006), Lisbon Strategy for Jobs and Growth: UK National Reform Programme: Update on Progress, London: HM Treasury.

HM Treasury (2007), Budget 2007: Building Britain's Long-term Future: Prosperity and Fairness for Families, London: Stationery Office.

Hudson, B. and Hardy, B. (2002), What is a 'successful' partnership and how can it be measured? In C. Glendinning, M. Powell and K. Rummery (eds), Partnerships, New Labour and the Governance of Welfare, Bristol: Policy Press, pp. 5 ${ }^{-6}-6$.

Hutchinson, J. and Campbell, M. (I998), Working in Partnership: Lessons from the Literature, Department for Education and Employment (DfEE) Research Report 63, London: DfEE.

Lindsay, C. (2007), The United Kingdom's 'Work First' welfare state and activation regimes in Europe. In A. Serrano Pascual (ed.), Reshaping Welfare States and Activation Regimes in Europe, Brussels: Peter Lang, pp. 35-70.

Lindsay, C., McQuaid, R. W. and Dutton, M. (2007), New approaches to employability in the UK: combining 'human capital development' and 'Work First' strategies? Journal of Social Policy, 36, 4: 539-6o. 
Lødemel, I. (200I), Discussion: workfare in the welfare state. In I. Lødemel and H. Trickey (eds), An Offer You Can't Refuse: Workfare in International Perspective, Bristol: Policy Press, pp. 294-343.

Lyons, S. T. and Hamlin, R. E. (I99I), Creating an Economic Development Action Plan, New York: Praeger.

McQuaid, R. W. (1994), Partnership and Urban Economic Development, Social Science Working Paper I3, Edinburgh: Napier University.

McQuaid, R. W. (2000), The theory of partnerships - why have partnerships? In S. P. Osborne (ed.), Managing Public-Private Partnerships for Public Services: An International Perspective, London: Routledge, pp. 9-36.

McQuaid, R. W. and Lindsay, C. (2005), The concept of employability, Urban Studies, 42, 2: 197-219.

McQuaid, R. W., Lindsay, C. and Greig, M. (2005), Job guarantees, employability training and partnerships in the retail sector, Local Economy, 20, I: 67-78.

Mason, M. (2007), Collaborative partnerships for urban development: a study of the Vancouver agreement, Environment and Planning A, 39, I0: 2366-82.

Miller, C. and Ahmad, Y. (2000), Collaboration and partnership: an effective response to complexity and fragmentation or a solution built on sand? International Journal of Social Policy and Sociology, 20, I: I-38.

Nelson, J. and Zadek, S. (200o), Partnership Alchemy: New Social Partnerships in Europe, Copenhagen: Copenhagen Centre.

Powell, M. and Dowling, B. (2006), New Labour's partnerships: comparing conceptual models and existing forms, Social Policy and Society, 5, 2: 305-14.

Powell, M. and Exworthy, M. (2002), Partnerships, quasi-networks and social policy. In C. Glendinning, M. Powell and K. Rummery (eds), Partnerships, New Labour and the Governance of Welfare, Bristol: Policy Press, pp. I5-32.

Ranade, W. and Hudson, B. (2003), Conceptual issues in inter-agency collaboration, Local Government Studies, 29, 3: 32-50.

Rhodes, J., Tyler, P. and Brennan, A. (2003), New developments in area-based initiatives in England: the experience of the SRB, Urban Studies, 40, 8: I399-I426.

Rummery, K. (2002), Towards a theory of welfare partnerships. In C. Glendinning, M. Powell and K. Rummery (eds), Partnerships, New Labour and the Governance of Welfare, Bristol: Policy Press, pp. 229-45.

Scottish Executive (2006), Workforce Plus: An Employability Framework for Scotland, Edinburgh: Scottish Executive.

Shaw, K. (2007), Joined up for Jobs - An Employability Agreement for Edinburgh, Local Economy, 22, 2: 188-94.

Somers, J. and Bradford, S. (2007), Discourses of partnership in multi-agency working in the community and voluntary sectors in Ireland, Irish fournal of Sociology, 15, 2: $67-85$.

Stoker, G. (I998), Public-private partnerships and urban governance. In J. Pierre (ed.), Partnerships in Urban Governance: European and American Experience, Basingstoke: Macmillan, pp. 34-51.

Sunley, P., Martin, R. and Nativel, C. (2006), Putting Workfare in Place: Local Labour Market and the New Deal, Oxford: Blackwell Publishing.

Taylor, M. (2006), Communities in partnership: developing a strategic voice, Social Policy and Society, 5, 2: 269-8o.

Trickey, H. and Walker, R. (200I), Steps to compulsion within British labour market policies. In I. Lødemel and H. Trickey (eds), An Offer You Can't Refuse: Workfare in International Perspective, Bristol: Policy Press, pp. I8I-2I4. 